triglyceride ở ngương tăng nặng (> $11 \mathrm{mmol} / \mathrm{l})$. Trong 6 ca bệnh, có 1 ca có đột biến trên gen $\mathrm{LPL}, 4$ ca đột biến mới trên gen GPIHPB1, $1 \mathrm{ca}$ có đột biến trên genApoE. Cả 6 ca bệnh đều đáp ứng với điều chỉnh chế độ ăn. Xác định đôt biến của các gen liên quan có giá trị khẳng định chẩn đoán, phòng bệnh bằng phát hiện dị hợp tử và tư vấn di truyền.

\section{TÀI LIÊU THAM KHẢO}

1. Lewis G.F., Changting X., Robert A.H. (2015). Hypertriglyceridemia in the genomic era: a new paradigm. Endocr Rev, 36(1), 131-47.

2. Davies B.S., Beigneux A.P., Barnes R.H et al. (2010). GPIHBP1 is responsible for the entry of lipoprotein lipase into capillaries. Cell Metab, 12, 42-52.

3. Peterfv M. (2012). Lipase maturation factor 1: a lipase chaperone involved in lipid metabolism. Biochim Biophys Acta, 1821, 790-4.

4. Vrablik M., Hubacek J.A. (2010). Genetic determination of triglyceridemia with special focus on apolipoprotein gene variants. Clinical Lipidology, 5(4), 543-54.

5. Shah A.S., Wilson D.P. (2015). Primary hypertriglyceridemia in children and aldolescents. J Clin lipidol, 9(5), S20-8.

6. Musambil M., Al-Rubeaan K., Al-Qasim S et al. (2020). Primary hypertriglyceridemia: A look back on the clinical classification and genetics of the disease. Curr Diabetes Rev, 16(6), 521-531.

\title{
SO SÁNH MộT Số TÁC DỤNG KHÔNG MONG MUỐN CỦA GÂY TÊ Cơ VUÔNG THẮT LƯNG VỚI GÂY TÊ MĂT PHẲNG CƠ NGANG BỤNG DƯớI HƯỚNG DẪN SIÊU ÂM ĐỂ GIẢM ĐAU SAU MỔ CẮT TỬ CUNG HOÀN TOÀN ĐƯờNG BỤNG
}

\section{TÓM TẮT}

Mục tiêu: So sánh một số tác dụng không mong muốn của phương pháp gây tê cớ vuông thắt lưng (QL block) với gây tê mặt phẳng cơ ngang bụng (TAP block) dưới hướng dẫn siêu âm để giảm đau sau mổ cắt tử cung hoàn toàn đường bụng. Đối tượng, phương pháp nghiên cứu: 60 bệnh nhân được gâyy tê tuỷ sông để phẫu thuật cắt tử cung hoàn toàn đường bụng, sau mổ được phân bố ngẩu nhiên vào hai nhóm bằng nhau để giảm đau sau mổ bằng $\mathrm{QL}$ block hai bên hoăc TAP block hai bên dưới hướng dẫn của siêu âm, sử dung ropivacain $0,25 \%$ liều $0,3 \mathrm{ml} / \mathrm{kg}$ ở mối bên. Theo dối liên tưc các tác dụng không mong muốn của hai phương pháp này trong 24 giờ đâu sau mổ. Kết quả: Tỷ lê nôn, buồn nôn ở nhóm QL block là 3,33\% so với nhóm TAP block là $6,67 \%$, tỷ lệ ngứa ở hai nhóm là 3,33\%. Không gặp trướng hợp nào bị tụ máu thành bụng, nhiễm khuẩn vị trí gây tê, tổn thương cơ quan trong ổ bụng hay ngộ độc thuốc tê ở cả hai nhóm nghiên cứu. Kết luận: Tác dụng không mong muốn của gây tê cơ vuông thắt lưng tương đương với gây tê mặt phẳng cơ ngang bụng dưới hướng dẫn của siêu ẩm để giảm đau sau mổ cắt tử cung hoàn toàn đường bụng. Không gặp các tai biến nặng nề của cả hai phương pháp này.

\section{${ }^{1}$ Trường Đại học Y Hà Nọi,}

${ }^{2}$ Bệnh viện Sản Nhi Nghệ An

Chiu trách nhiệm chính: Nguyễn Đức Lam

Email: lamgmhs75@gmail.com

Ngày nhận bài: 4.01.2021

Ngày phản biên khoa học: 26.2.2021

Ngày duyệt bài: 9.3.2021

\section{Nguyễn Đức Lam", Trần Thị Phương²}

Tư khoá: Gây tê cơ vuông thắt lưng, gây tê mặt phẳng cơ ngang bụng , cắt tử cung hoàn toàn đường bụng, tác dụng khổng mong muốn.

\section{SUMMARY \\ THE COMPARISON OF THE SIDE EFFECTS \\ OF ULTRASOUND GUIDED QUADRATUS LUMBORUM BLOCK VERSUS TRANSVERSUS ABDOMINIS PLANE BLOCK FOR PAIN RELIEF IN TOTAL ABDOMINAL HYSTERECTOMY}

Objective: To compare the side effects of ultrasound guided Quadratus lumborum (QL) block versus Transversus Abdominis Plane (TAP) block for pain relief of total abdominal hysterectomy. Methods: 60 patients performed spinal anesthesia for total abdominal hysterectomy, were randomly divided into two similar groups to receive analgesia postoperative by ultrasound guided bilateral QL block or bilateral TAP block with ropivacaine $0.25 \%$ dose of $0.3 \mathrm{ml} / \mathrm{kg}$ on each side. We Continuously monitored the side effects of these methods in the first 24 hours after surgery. Results: The rate of nausea and vomiting in the QL block group was 3.33\% compared to $6,67 \%$ in TAP block group the pruritus rate in the two groups was $3.33 \%$. There was no case of abdominal wall hematoma, infection on the needle punture site, intra-abdominal organ damage or local anaesthetic systemic toxicity in both groups. Conclusions: The side effects of ultrasound guided Quadratus lumborum (QL) block was similar to Transversus Abdominis Plane (TAP) block for postoperative pain relief in total abdominal hysterectomy. There was no serious complication in 
both methods.

Keywords: Quadratus lumborum block (QLB), Transversus Abdominis Plane block (TAPB), total abdominal hysterectomy, side effects, ultrasound guided.

\section{I. ĐĂT VẤN ĐỀ}

Giảm đau sau mổ không chỉ giúp người bệnh giảm đau đớn mà còn giúp người bênh phục hồi sớm sau mổ góp phần quan trong vào thành công của phẫu thuật. Phẫu thuật cắt tử cung toàn bộ được coi là một trong những phẫu thuật bung lớn gây ra mức độ đau vừa và nă̆ng, do đó, cần phải có các biên pháp giảm đau có hiệu quả để giảm đau tốt nhất cho người bệnh và hạn chế tác dụng không mong muốn. TAP block (Transverse Abdominis Plane block) là kỹ thuât gây tê ngoại vi, không ức chế giao cảm, ít tác dụng không mong muốn, tác dụng giảm đau thành bung khá tốt đăc biệt 24 giờ đâu sau mổi ${ }^{1}$, tuy nhiên, phương pháp này chỉ giảm đau được thành bung mà không giảm đau được các tang trong ổ bụng. Gây tê cơ vuông thắt lưng (Quadratus lumborum - QL block) là một cải tiến của TAP block nên có cả tác dung giảm đau thành bung và giảm đau một số tang trong ổ bụng, vì vậy, ngày càng được áp dụng rộng rãi. Hiên nay, ở trên thế giới có nhiều nghiên cứu về vấn đề này, tuy nhiên, ở Việt Nam có rất ít nghiên cứu về hai phương pháp giảm đau này cho người bệnh sau mổ cắt tử cung hoàn toàn đường bụng, đặc biệt là nghiên cứu các tác dụng không mong muốn của hai phương pháp này. Vì vậy, chúng tôi thực hiện nghiên cứu này nhằm mục tiêu: So sánh một số tác dụng không mong muốn của giảm đau sau mổ cắt tử cung hoàn toàn đường bưng bằng phương pháp gây tê cơ vuông thắt lưng so với gây tê mặt phẳng cơ ngang bụng bằng ropivacain 0,25\% dưới hướng dẫn của siêu âm.

\section{II. Đốl TƯợNG VÀ PHƯƠNG PHÁP NGHIÊN CỨU \\ 1. Đối tượng nghiên cứu}

Tiêu chuẩn lựa chọn: Các bệnh nhân có chỉ định phẫu thuật cắt tử cung hoàn toàn đường bụng, được mổ đường ngang trên vệ (đường mổ Pfannenstiel). ASA I, II tuổi từ $18-60$ tuổi.

Tiêu chuân loại trừ: Có bệnh đau mạn tính thường xuyên phải sử dụng thuốc giảm đau. Đang dùng thuốc giảm đau ho opiod hoặc thuốc IMAO ngay trước mổ. Có chống chỉ định của gây tê thần kinh, dị ứng thuốc tê. $\mathrm{BN}$ được chẩn đoán ung thư tử cung hoăcc ung thư buồng trứng.

\section{Phương pháp nghiên cứu}

Thiêt kế nghiên cứu: Nghiên cứu thử nghiệm lâm sàng, ngẫu nhiên có so sánh.
Địa điểm, thời gian nghiên cứu: Tại khoa Gây mê Hồi sức, khoa Phụ ngoại, khoa Phụ ngoại theo yêu câu, bênh viện Phụ sản Hà Nội từ $8 / 2019$ đến tháng $8 / 2020$.

Cỡ mẫu: 60 bệnh nhân được bốc thăm ngẫu nhiên chia đều thành 2 nhóm, nhóm 1 được giảm đau bằng phương pháp gây tê cơ vuông thắt lưng (QL block), nhóm 2 được giảm đau bằng phương pháp gây tê mặt phẳng cơ ngang bụng (TAP block).

Cách thức tiến hành: Các bênh nhân đều được vô cảm để mổ cắt tử cung hoàn toàn đường bụng bằng gây tê tủy sống (Gây tê ở L23 , thuốc tê bupivacain $10 \mathrm{mg}$ và fentanyl 40 $\mathrm{mcg}$ ). Sau mổ được theo dõi liên tục ở phòng Hồi tỉnh và được gây tê để giảm đau bằng hai phương pháp trên khi đã hết tác dụng của gây tê tủy sống (Phục hồi ức chế cảm giác ở mức D12). Tất cả các bênh nhân của cả hai nhóm đều được gây tê hai bên thành bụng với liều thuốc tê mối bên là $0,3 \mathrm{ml} / \mathrm{kg}$ ropivacain $0,25 \%$, không quá $20 \mathrm{ml}$.

Nhóm QL bloc gây tê theo phương pháp QL 2 (tiêm thuốc tê vào mă̆t sau cơ vuông thắt lưng), bệnh nhân nằm nghiêng khi gây tê, sử dụng đâu dò siêu âm cong, mốc xác định cơ vuông thắt lưng là mỏm ngang đốt sống và dấu hiêu "ngón tay".

Nhóm TAP bloc, gây tê ở vị trí đường ngang rốn, bệnh nhân ở tư thế nằm ngửa, sử dụng đâu dò siêu âm thẳng, mốc xác định là ba lớp cơ thành bung.

Sau khi gây tê, các bệnh nhân đều được giảm đau phối hợp bằng phương pháp giảm đau do bênh nhân tự kiểm soát (PCA) với morphine 1 $\mathrm{ml} / 1 \mathrm{mg}$ đường tĩnh mạch (thông số cài đặt máy PCA: liêu bolus là $1 \mathrm{ml}$, thời gian khóa là 8 phút, liều tối đa trong 4 giờ là $15 \mathrm{mg}$ ).

Các chỉ tiêu nghiên cứu: Các đặc điểm chung của đối tượng nghiên cứu (Tuổi, BMI, ASA, thời gian phẫu thuật...). Các tác dụng không mong muốn và biến chứng của cả hai phương pháp như: Ảnh hưởng lên tuần hoàn, hô hấp, nôn, buồn nôn, ngứa, tụ máu, nhiễm trùng do gây tê, ngộ độc thuốc tê, tổn thương các tạng trong ổ bụng do kim gây tê...

Xử lý số liệu: Sử dụng phần mềm thống kê SPSS 20.0. Với các biến định lượng dùng thuật toán T-student. Với các biến đinh tính: X2 hoặc Fisher. Sự khác biệt có ý nghĩa thống kê khi $p<0,05$.

Đạo đức nghiên cứu: Nghiên cứu đã được thông qua Hội đồng $Y$ đức của Bệnh viện Phụ sản Hà Nội và đảm bảo các nguyên tắc về $y$ đức trong nghiên cứu y sinh học. 
III. KẾT QUẢ NGHIÊN CỨU

1. Đặc điểm chung, đặc điểm về phẫu thuật và gây mê hồi sức của hai nhóm nghiên cứu Bảng 1. Đặc điểm chung, đặc điểm về phẩu thuật và gây mê hồi sức

\begin{tabular}{|c|c|c|c|c|}
\hline \multicolumn{2}{|c|}{ Đặc điểm Nhóm } & $\begin{array}{l}\text { QL block } \\
\left(n_{1}=30\right)\end{array}$ & $\begin{array}{l}\text { TAP block } \\
\left(\mathrm{n}_{2}=30\right)\end{array}$ & $\mathbf{p}$ \\
\hline ASA & $\bar{X} \pm \mathrm{SD}$ & $1,33 \pm 0,48$ & $1,27 \pm 0,50$ & $>0,05$ \\
\hline Tuối (năm) & $\bar{X} \pm \mathrm{SD}$ & $47,47 \pm 5,18$ & $47,13 \pm 4,93$ & $>0,05$ \\
\hline BMI & $\bar{X} \pm S D$ & $21,59 \pm 2,45$ & $21,04 \pm 1,92$ & $>0,05$ \\
\hline \multirow{3}{*}{ Chỉ định phẫu thuật } & $\mathrm{U} x \sigma$ tử cung to & $20(66,7 \%)$ & $21(70 \%)$ & $>0,05$ \\
\hline & Lạc nội mạc tử cung & $7(23,3 \%)$ & $8(26,7 \%)$ & $>0,05$ \\
\hline & U xớ TC + u buồng trứng & $3(10 \%)$ & $1(3,3 \%)$ & $>0,05$ \\
\hline $\begin{array}{l}\text { Thời gian phâu thuật } \\
\text { (phút) }\end{array}$ & $\bar{X} \pm S D$ & $68 \pm 11,64$ & $70,83 \pm 10,51$ & $>0,05$ \\
\hline $\begin{array}{l}\text { Thời gian vô cảm của } \\
\text { gây tê tủy sống }\end{array}$ & $\bar{X} \pm S D$ & $175,3 \pm 41,1$ & $179,1 \pm 38,5$ & $>0,05$ \\
\hline $\begin{array}{l}\text { Liêu Bupivacain trong } \\
\text { gây tê tủy sông }\end{array}$ & $\bar{X} \pm S D$ & $10,1 \pm 0,25$ & $10 \pm 0,1$ & $>0,05$ \\
\hline \multirow{3}{*}{$\begin{array}{c}\text { Tiên sử liên quan đến } \\
\text { nôn, buồn nôn sau } \\
\text { mố }\end{array}$} & tàu xe & $27(90 \%)$ & $28(93,3 \%)$ & $>0,05$ \\
\hline & Hút thuốc lá & 0 & 0 & \\
\hline & Nôn, buồn nôn sau mố & 0 & 0 & \\
\hline
\end{tabular}

Nhận xét: Không có sự khác biệt có ý nghĩa thống về ASA, tuối, BMI và các đặc điểm về phầu thuật và gây mê hồi sức của các bệnh nhân ở hai nhóm nghiên cứu.

\section{Tác dụng không mong muốn \\ 2.1. Ảnh hưởng đến mạch và huyêt áp của bệnh nhân}

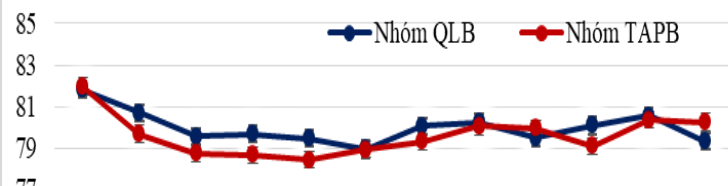

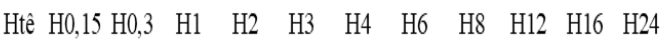

Biểu đồ 1. Tần số tim trung bình của các bệnh nhân trong thời gian nghiên cứu

$\rightarrow$ Nhóm QLB $\rightarrow$ Nhóm TAPB

80

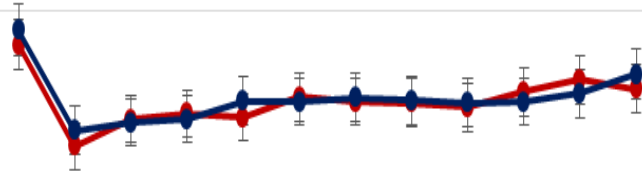

70

Htê H0.15 H0.3 H1 H2 H3 H4 H6 $\quad$ H8 H12 H16 H24

Biểu đồ 2. Tân số huyêt áp động mạch trung bình của các bệnh nhân trong thời gian nghiên cứu

Nhân xét: Không có sự khác biệt có ý nghĩa thống kê về tần số tim và huyết áp trung bình của các bệnh nhân giữa hai nhóm tại tất cả các thời điểm nghiên cứu.
2.2. Ảnh hưởng đến hô hấp của bênh nhân (tân số thở và độ bão hoà oxy mao mạch)

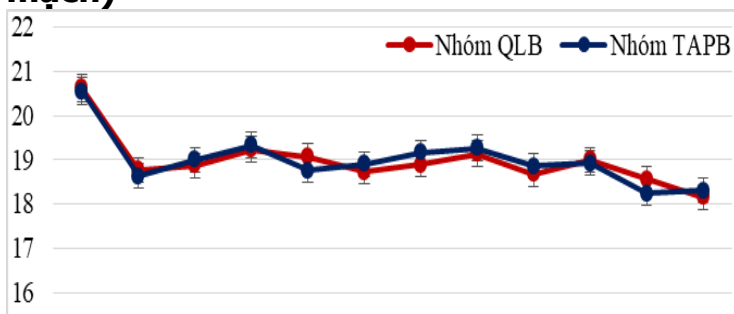

$\begin{array}{llllllllll}\text { Htê H0,15 H0,3 H1 H2 } & \text { H3 } & \text { H4 } & \text { H6 } & \text { H8 } & \text { H12 } & \text { H16 } & \text { H24 }\end{array}$

Biểu đồ 3. Tân số thở của các bệnh nhân trong thời gian nghiên cứu

100

$\multimap$ Nhóm QLB $\multimap$ Nhóm TAPB

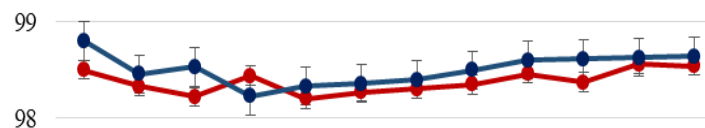

97

Htê H0,15 H0,3 H1 H2 H3 H4 H6 H8 H12 H16 H24

Biểu đồ 4. Bão hòa oxy mao mạch của các bênh nhân trong thời gian nghiên cứu

Nhận xét: Không có sự khác biệt có ý nghĩa thống kê về tần số thở và $\mathrm{SpO}_{2}$ trung bình của các bệnh nhân trong tất cả các thời điểm nghiên cứu. Không gặp bệnh nhân ngừng thở hoặc có tần số thở dưới 10 lần/phút, không gặp bệnh nhân $\mathrm{SpO}_{2}<90 \%$. 

khác

2.3. Một số tác dụng không mong muốn

Bảng 2. Một số tác dụng không mong muốn khác

\begin{tabular}{|c|c|c|c|}
\hline $\begin{array}{l}\text { Tác dưng } \\
\text { không mong } \\
\text { muốn }\end{array}$ & $\begin{array}{c}\text { Nhóm } \\
\text { QLB } \\
\left(\mathbf{n}_{\mathbf{1}}, \mathbf{\%}\right)\end{array}$ & $\begin{array}{c}\text { Nhóm } \\
\text { TAPB } \\
\left(\mathbf{n}_{\mathbf{2}}, \mathbf{\%}\right)\end{array}$ & $\mathbf{p}$ \\
\hline Nôn, buồn nôn & $1(3,33 \%)$ & $2(6,67 \%)$ & $>0,05$ \\
\hline Ngứa & $1(3,33 \%)$ & $1(3,33 \%)$ & $>0,05$ \\
\hline Tự máu & 0 & 0 & \\
\hline Nhiềm trùng & 0 & 0 & \\
\hline Suy hô hấp & 0 & 0 & \\
\hline $\begin{array}{c}\text { Tô̂n thương các } \\
\text { cơ quan }\end{array}$ & 0 & 0 & \\
\hline Ngộ độc thuốc tê & 0 & 0 & \\
\hline
\end{tabular}

Nhận xét: Không có sự khác biệt có ý nghĩa thống kê về tỷ lệ nôn, buồn nôn và ngứa giữa hai nhóm. Không gặp các biến chứng nguy hiểm của gây tê vùng ở cả hai nhóm.

\section{BÀN LUẬN}

Các bệnh nhân ở hai nhóm trong nghiên cứu của chúng tôi có các đặc điểm chung về tuổi, chiều cao, cân nặng và phân loại sức khỏe theo ASA khá tương đồng nhau. Đa số các bệnh nhân đều chỉ định phẫu thuật cắt tử cung hoàn đường bunng do u xơ tử cung $(76,7 \%$ ở nhóm QL block so với 73,3\% ở nhóm TAP block). Các yếu tố liên quan đến gây mê và phẫu thuật cũng không có sự khác biệt có ý nghĩa thống kê $(p>0,05)$. Cả hai phương pháp đều thành công $100 \%$, lượng thuốc tê trung bình sử dụng của nhóm QL block là $78,45 \pm 9,5 \mathrm{mg}$ và $78,5 \pm 7,28 \mathrm{mg}$ của nhóm TAP block, không có sự khác biệt giữa hai nhóm $(p>0,05)$. Kết quả này cũng phù hợp với kết quả của Ueshima $\mathrm{H}^{6}$. Liều lượng chúng tôi sử dụng là $1,5 \mathrm{mg} / \mathrm{kg}$, liều này có lẽ phù hợp với thể trạng người Việt Nam và không vượt quá ngưỡng gây độc của thuốc tê ropivacain đã khuyến cáo $(150 \mathrm{mg})$, do đó, sẽ giảm thiểu các tác dụng không mong muốn liên quan đến liều thuốc tê.

Tần số tim và huyết áp trung bình của các bệnh nhân ở cả hai nhóm nghiên cứu của chúng tôi tại tất cả các thời điểm nghiên cứu đều trong giới hạn bình thường và không có sự khác biệt có ý nghĩa thống kê $(p>0,05)$. Kết quả của chúng tôi tương đồng với kết quả nghiên cứu của các tác giả Aditianingsih ${ }^{1}$, Ueshima $\mathrm{H}^{6}$ : $\mathrm{QL}$ block và TAP block không làm thay đổi huyết áp trung bình và tần số tim của bệnh nhân. Tần số thở và bão hòa ôxy mao mạch $\left(\mathrm{SpO}_{2}\right)$ trung bình tại các thời điểm của cả hai nhóm đều trong giới hạn bình thường và cũng không thấy sự khác biệt có ý nghĩa thống kê giữa hai nhóm ( $p$ > $0,05)$. Chúng tôi cũng không gặp trường hợp nào bệnh nhân có $\mathrm{SpO}_{2}<90 \%$ hoặc ngừng thở hay có tần số thở dưới 10 lần/phút. Đây là ưu điểm của phương pháp gây tê QL block, TAP block so với gây tê tủy sống hoặc gây tê ngoài màng cứng do cơ chế tác dụng giảm đau là phong bế các nhánh thần kinh cảm giác ở ngoại vi và không sử dụng phối hợp với các thuốc họ morphin.

Trong nghiên cứu của chúng tôi các yếu tố liên quan đến nguy cơ buồn nôn và nôn như: Giới, tiền sử hút thuốc, say tàu xe, lượng thuốc sử dụng trong vô cảm để mổ, loại và thời gian phẫu thuật là tương đối đồng nhất giữa hai nhóm, do đó, không ảnh hưởng đến kết quả nghiên cứu. Kết quả nghiên cứu của chúng tôi cho thãy tỷ lệ buồn nôn, nôn trong 24 giờ sau mổ ở nhóm QL block là 3,33\% và nhóm TAP block là 6,67\%, không có sự khác biệt có ý nghĩa (p> 0,050. Junheng Cheng ${ }^{4}$ tổng hợp bốn nghiên cứu gồm 304 bệnh nhân so sánh hai phương pháp gây tê QL block và TAP block cho thấy tỷ lệ bị nôn, buồn nôn không có sự khác biệt $(R R=0,55$; khoảng tin cậy $95 \%=0,27$ $1,14 ; p=0,11)$. Tỉ lệ bệnh nhân có triệu chứng ngứa là 3,33\% ở cả 2 nhóm đối tượng nghiên cứu, không có sự khác biệt có ý nghĩa với $\mathrm{p}>$ 0,05 . Đa số các bệnh nhân bị ngứa ở vùng mặt và ngực mức độ nhẹ, nguyên nhân có thể do tác dụng phụ của fentanyl sử dụng khi gây tê tủy sống và thường triệu chứng này không cần phải điều trị.

Trong nghiên cứu này chúng tôi không gặp trường hợp nào bi ngô độc thuốc tê. Kỹ thuật tiến hành thuận lợi dưới hướng dẫn của siêu âm nên không có trường hợp nào tiêm vào mạch máu, phúc mạc, tổn thương gan thận ruột hoặc tiêm ra ngoài mặt phẳng cơ ngang bụng và khoang cơ vuông thắt lưng. Một vài nghiên cứu đã chỉ ra nồng độ thuốc tê trong huyết tương khi gây tê cơ vuông thắt lưng thấp hơn nhiều khi gây tê mặt phẳng cơ ngang bụng ${ }^{2,5}$. Uuu điểm của phương pháp gây tê khoang cơ vuông thắt lưng là khoang này nằm tương đối xa khoang phúc mạc nên việc tổn thương tạng, thần kinh lớn là rất hiếm. Các nghiên cứu khác cũng chỉ ra điều đó, do đó người ta chấp nhận QL block có thể thực hiện dưới gây mê hoặc bệnh nhân tỉnh ${ }^{3}$. Kết quả của chúng tôi cũng tương tự các nghiên cứu hiện nay với gây tê TAP block dưới hướng dẫn của siêu âm cho thấy những biến chứng là cực kỳ hiếm gặp ${ }^{4}$, tuy nhiên, do sử dụng liều 
lượng thuốc tê khá cao và tiêm môt lần duy nhất nên dù đã có hướng dẫn của siêu âm nhưng vẫn cần tuyệt đối tuân thủ các nguyên tắc của gây tê vùng để đề phòng biến chứng ngộ độc thuốc tê do tiêm thuốc tê vào mạch máu.

\section{KẾT LUẬN}

Tác dụng không mong muốn của phương pháp gây tê cơ vuông thắt lưng (QL block) hai bên bằng ropivacain $0,25 \%$ (liều $0,3 \mathrm{ml} / \mathrm{kg}$ mỗi bên) tương đương với phương pháp gây tê mặt phẳng cơ ngang bụng (TAP block) hai bên bằng thuốc tê và liều tương tự, dưới hướng dẫn của siêu âm để giảm đau sau mổ cắt tử cung hoàn toàn đường bụng. Không gặp các tai biến nặng nề của cả hai phương pháp này.

\section{TÀI LIÊU THAM KHẢO}

1. Aditianingsih D, Mochtar CA, Chandra S, et al. Comparison of Three-Quadrant Transversus Abdominis Plane Block and Continuous Epidural Block for Postoperative Analgesia After Transperitoneal Laparoscopic Nephrectomy.
Anesth Pain Med. 2018;8(5):e80024. doi:10.5812/ aapm.80024

2. Charlton S, Cyna AM, Middleton P, et al. Perioperative transversus abdominis plane (TAP) blocks for analgesia after abdominal surgery. Cochrane Database Syst Rev. 2010; 12, Cd007705.

3. Chen J, Chen $\mathbf{C}$, Sun $\mathbf{G}$, et al. Quadratus Lumborum Block Versus Transversus Abdominis Plane Block for Postoperative Analgesia in Abdominal Surgery: A Systematic Review and Meta-analysis. BMC Anesthesiol, 2020 Mar 2;20(1):53 https://orcid.org/0000-0002-6001-4530.

4. Chin KJ, McDonnell JG, Carvalho B, et al. Essentials of Our Current Understanding: Abdominal Wall Blocks. Reg Anesth Pain Med. 2017;42(2):133-183. doi:10.1097/AAP.0000000000000545

5. Murouchi $T$, Iwasaki $S$, Yamakage $M$. Quadratus Lumborum Block: Analgesic Effects and Chronological Ropivacaine Concentrations After Laparoscopic Surgery. Reg Anesth Pain Med. 2016;41(2):146-150. doi:10.1097/AAP.0000000000000349.

6. Ueshima $H$, Otake $H$, Lin JA. UltrasoundGuided Quadratus Lumborum Block: An Updated Review of Anatomy and Techniques. Biomed Res Int 2017:2752876. 2017; Epub 2017 Jan 3.

\section{ĐĂC ĐIỂM HİNH THÁI RĂNG SỐ 8 MỌC LỆCH VÀ BIẾN CHỨNG TỚI RĂNG SỐ 7 HÀM DƯỚI TRÊN PHIM PANORAMA}

\section{TÓM TẮT}

Vị trí mọc bất thường của răng số 8 gây ra nhiều biến chứng, ảnh hưởng trực tiếp tới sức khỏe của người bênh nhân. Kỹ thuât chup phim răng Panorama đem đến nhiêu lợi ích cho Bác sĩ răng hàm mặt khi khám xét về hình thái răng số 8 , các cấu trúc và những tổn thương lân cận. Nghiên cứu được tiến hành dưa trên kết quả đo đạc của 119 bệnh nhân có chụp phim Panorama. Kết quả của chúng tôi chỉ ra răng số 8 mọc lệch gặp nhiều nhất ở lứa tuổi từ 26-40 tuổi chiếm tỷ lệ $52.94 \%$, mọc lệch gần-góc chiếm tỷ lệ cao nhất $63.26 \%$, mọc nằm ngang $21.95 \%$ và ngâm ngược chiếm tỷ lệ thấp nhất $1.53 \%$. Răng số 8 mọc lệch $>45^{\circ}$ chiếm tỷ lê đa số $62.76 \%$, lệch $46^{\circ}-80^{\circ}$ chiếm tỷ lệ $54.08 \%$.Biển chứng sâu răng chiếm tỷ lể cao nhất $52.88 \%$, sau đó là tốn thương tiêu xương ổ răng chiếm $47.12 \%$, tỷ lệ sâu chưa tổn thương tủy răng 7 chiếm $46.60 \%$, tổn thương đến tủy răng số 7 chiếm $6.28 \%$. Tiêu tổ chức cứng không gặp trong nghiên cứu này. Trong số các biến chứng gặp phải,

*Trường Đại học Kỹ thuật Y tễ Hải Dương Chiu trách nhiệm chính: Nguyễn Hải Niên Email: Nguyenhainien1981@gmail.com Ngày nhận bài: 6.01.2021

Ngày phản biện khoa học: 25.2.2021

Ngày duyệt bài: 8.3.2021

\section{Nguyễn Hải Niên*, Phạm Hữu Thiên*}

biến chứng sâu răng số 7 gặp đa số khi răng số 8 mọc ở tư thế lệch gần-góc chiếm tỷ lệ 69.31\%.

\section{SUMMARY}

THE STUDY OF MORPHOLOGICAL CHARACTERISTICS OF WISDOM TEETH DEVIATE AND COMPLICATIONS AT THE LOWER TTH TEETH IN THE PANORAMA XRAY FILMS

The abnormal erupting position of the No. 8 tooth causes many complications, directly affecting the patient's health. The Panorama dental imaging technique brings many benefits to the orthodontist when examining teeth morphology No. 8, structures and neighboring lesions. The study was conducted based on the measurements of 119 patients with Panorama film. Our results show that the number 8 is most common at the age of $26-40$ years old, accounting for $52.94 \%$, the rate of nearly-angular deviation accounts for the highest rate $63.26 \%$, horizontal growth of $21.95 \%$ and inverted accounting for the lowest rate of $1.53 \%$. Tooth number 8 is deviated $>45^{\circ}$, accounting for the majority of $62.76 \%$, deviation $46^{0}-80^{\circ}$ accounts for $54.08 \%$. Caries complications accounted for the highest rate of $52.88 \%$, followed by alveolar bone resorption, which accounted for $47.12 \%$, the proportion of cavities without damage to tooth marrow 7 accounted for $46.60 \%$, and damage to tooth pulp number 7 